\title{
Intensification of Summer Rainfall Variability in the Southeastern United States during Recent Decades
}

\author{
HUI WANG \\ NOAA/NWS/NCEP/Climate Prediction Center, Camp Springs, Maryland, and Wyle Information \\ Systems, McLean, Virginia \\ RONG FU \\ Department of Geological Sciences, The University of Texas at Austin, Austin, Texas \\ ARUN KUMAR \\ NOAA/NWS/NCEP/Climate Prediction Center, Camp Springs, Maryland \\ WENHONG LI \\ Earth and Ocean Sciences, Nicholas School, Duke University, Durham, North Carolina
}

(Manuscript received 29 October 2009, in final form 1 March 2010)

\begin{abstract}
The variability of summer precipitation in the southeastern United States is examined in this study using 60-yr (1948-2007) rainfall data. The Southeast summer rainfalls exhibited higher interannual variability with more intense summer droughts and anomalous wetness in the recent 30 years (1978-2007) than in the prior 30 years (1948-77). Such intensification of summer rainfall variability was consistent with a decrease of light $\left(0.1-1 \mathrm{~mm} \mathrm{day}^{-1}\right)$ and medium $\left(1-10 \mathrm{~mm} \mathrm{day}^{-1}\right)$ rainfall events during extremely dry summers and an increase of heavy $\left(>10 \mathrm{~mm} \mathrm{day}^{-1}\right)$ rainfall events in extremely wet summers. Changes in rainfall variability were also accompanied by a southward shift of the region of maximum zonal wind variability at the jet stream level in the latter period. The covariability between the Southeast summer precipitation and sea surface temperatures (SSTs) is also analyzed using the singular value decomposition (SVD) method. It is shown that the increase of Southeast summer precipitation variability is primarily associated with a higher SST variability across the equatorial Atlantic and also SST warming in the Atlantic.
\end{abstract}

\section{Introduction}

The southeastern United States is one of the fastest growing regions in the nation. Water supplies in this area are increasingly stressed, especially during summer. The year-to-year fluctuations in summer rainfall over the Southeast thus have vital influence on regional hydrology, agriculture, and related industries. During the past three decades, summer droughts repeatedly struck the Southeast, causing devastating socioeconomic impacts on this region. For example, the 1986 Southeast summer drought caused billions of dollars of damage in

Corresponding author address: Dr. Hui Wang, NOAA/Climate Prediction Center, 5200 Auth Road, Camp Springs, MD 20746. E-mail: hui.wang@noaa.gov agriculture (Bergman et al. 1986; Karl and Young 1987). The 2000 drought caused a 40\% reduction in Georgia's crop production and $\$ 739$ million in economic loss in a single state (McKissick et al. 2000). The recent 2007 drought ranked as the worst in 100 years and pushed water shortages to a crisis point. This extreme drought was followed by floods in Georgia in late summer 2009.

The recurrence of severe droughts in recent decades raises the question as to whether the variability of precipitation in the Southeast has changed. If so, what factors may contribute to such changes? This study aims to characterize the shift in summer rainfall variability in the U. S. Southeast and to explore the link between changes in rainfall variations and the variability of sea surface temperature (SST). 
Compared to warm season rainfall in the Great Plains (e.g., Namias 1983; Chang and Wallace 1987; Laird et al. 1996) and the North American monsoon region (Higgins et al. 2003), the variability of Southeast summer precipitation has received less attention. In terms of seasonal mean precipitation and its variability, however, summer rainfall in the Southeast constitutes an important part of warm season precipitation over the continental United States. As shown in Fig. 1a, summer U.S. precipitation is characterized by abundant rainfall $\left(>4 \mathrm{~mm} \mathrm{day}^{-1}\right)$ along the southeastern coast. The seasonal mean precipitation increases from less than $1 \mathrm{~mm}$ day $^{-1}$ in the Southwest to more than $5 \mathrm{~mm} \mathrm{day}^{-1}$ in the southeast corner. In the central and eastern United States, precipitation is generally above $3 \mathrm{~mm}$ day $^{-1}$. Figure $1 \mathrm{~b}$ shows the variance of summer precipitation. High interannual variability is found in both the central and southeastern United States. A better understanding of the Southeast summer precipitation variability is thus essential for (i) improving prediction of U.S. warm season rainfall and (ii) addressing whether trends in rainfall are related to the periodic natural variability of the climate system or are due to warming of tropical oceans associated with anthropogenic causes.

Previous studies have not reached a consensus on what causes variability of the summer rainfall over the southeastern United States, especially the impact of Atlantic SST anomalies. For example, recent observational and modeling studies indicate that summer droughts and associated rainfall anomalies in the Southeast are less persistent (Mo and Schemm 2008) and they are primarily controlled by internal atmospheric variability (Seager et al. 2009). It is also found that there is no significant correlation between Southeast summer precipitation and SSTs computed over a long period (Seager et al. 2009). However, other studies suggest that the interannual variation of Southeast summer precipitation may be correlated with SSTs over a shorter period (2-3 decades), but its relation to SST varies on multidecadal scales (Hu and Feng 2001).

Enfield (1996) illustrated that tropical North Atlantic SST anomalies have a significant impact on Southeast rainfall at interannual time scales that is independent of Pacific SSTs. Long-term droughts and associated rainfall and river flows in the Southeast are also linked to the Atlantic multidecadal oscillation (AMO) (Enfield et al. 2001; McCabe et al. 2004). Associated with a warm phase of the AMO, the intensity of precipitation tends to increase in Florida and the southeast coastal region (Curtis 2008). The basin-scale changes in Atlantic SSTs are shown to be an important forcing of North American summer multidecadal climate variability (Sutton and Hodson 2005), including changes in precipitation and temperature

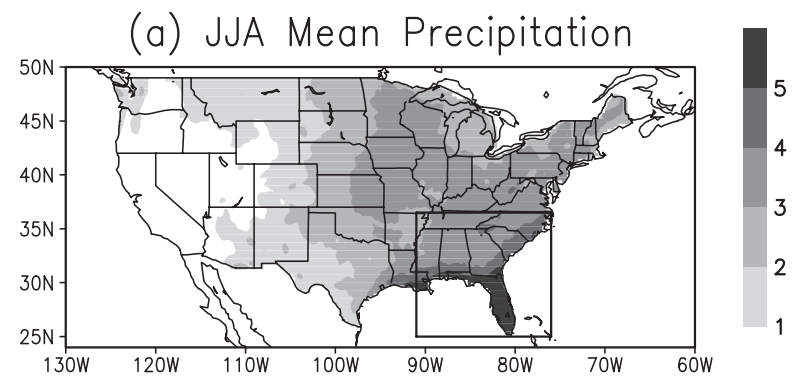

(b) Variance

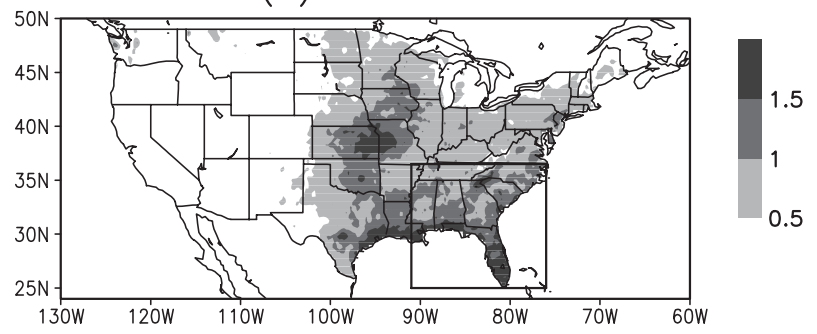

FIG. 1. June-August (a) mean $\left(\mathrm{mm} \mathrm{day}^{-1}\right)$ and (b) variance $\left(\mathrm{mm}^{2} \mathrm{day}^{-2}\right)$ of U.S. precipitation based on rainfall data from 1948 to 2007 . The box $\left(25^{\circ}-36.5^{\circ} \mathrm{N}, 76^{\circ}-91^{\circ} \mathrm{W}\right)$ indicates the region of land used to construct the Southeast precipitation index.

in the Southeast. This study aims to characterize the intensification of Southeast summer rainfall variability, including more severe droughts in recent decades, and its connection to the variation of tropical Atlantic SSTs. We note that the inferred associations between rainfall and SST variability do not imply causality, and may be a different manifestation of long-term natural variability of the coupled climate system.

\section{Data and method}

The data used in this study consist of precipitation, atmospheric wind field, and SSTs from 1948 to 2007. Summer seasonal means are obtained by averaging together the monthly means of June-August (JJA). An anomaly is defined as the deviation of a seasonal mean from its 60 -yr long-term climatology. The U.S. precipitation data are taken from the National Oceanic and Atmospheric Administration (NOAA) Climate Prediction Center (CPC) U.S. Unified Precipitation for 1948-98 and from the real time U.S. Daily Precipitation Analysis for 1999-2007. Both datasets are on a $0.25^{\circ} \times 0.25^{\circ}$ (latitude $\times$ longitude) grid. The atmospheric winds are from the National Centers for Environmental PredictionNational Center for Atmospheric Research (NCEPNCAR) reanalysis product (Kalnay et al. 1996) on a $2.5^{\circ} \times 2.5^{\circ}$ grid. The SSTs are the NOAA Extended Reconstructed SST (ERSST version 3) (Smith et al. 2008) with a $2^{\circ} \times 2^{\circ}$ (latitude $\times$ longitude) resolution. 
The relationship between Southeast summer precipitation and SSTs is examined by using singular value decomposition (SVD) (Bretherton et al. 1992). This statistical technique objectively identifies pairs of spatial patterns of precipitation and SSTs with maximum temporal covariance between the two fields (e.g., Ting and Wang 1997; Wang and Ting 2000). Linear and multiple linear regressions are employed to composite and reconstruct anomalous atmospheric circulation and precipitation based on one or multiple base time series. The significance of the statistical results is estimated by the Monte Carlo technique (e.g., Wilks 1995).

\section{Results}

\section{a. Variability of Southeast summer precipitation}

To describe the variability of summer rainfall in the Southeast, a precipitation index is constructed by averaging June-August monthly-mean precipitation anomalies in an area from $76^{\circ}$ to $91^{\circ} \mathrm{W}, 25^{\circ}$ to $36.5^{\circ} \mathrm{N}$. The area covers seven southeastern states, including Alabama, Florida, Georgia, Mississippi, North Carolina, South Carolina, and Tennessee. Whether the area-averaged rainfall anomalies represent the interannual variability of seasonal mean precipitation in the Southeast is examined by calculating the correlation between the precipitation index and JJA seasonal mean precipitation at every grid point over the United States. The correlation map (not shown) displays coherent and significant correlations in all the seven southeastern states.

The normalized index time series for the 60 years (1948-2007) is shown in Fig. 2a, with one standard deviation corresponding to $0.64 \mathrm{~mm} \mathrm{day}^{-1}$. The precipitation index displays higher interannual variability with more wet and dry extremes in the second half of the period (1978-2007). In the first $30 \mathrm{yr}$ (1948-77), there were only two wet and two dry summers with rainfall anomalies exceeding one standard deviation. In the second $30 \mathrm{yr}$, however, there were six wet and five dry summers with rainfall anomalies greater than one standard deviation. The summer precipitation in the second half of the period contributes to the total rainfall variance by $68 \%$, in contrast to $32 \%$ in the first $30 \mathrm{yr}$.

To quantify characteristics of droughts, shown in Figs. $2 b$ and $2 c$ are the corresponding time series of JJA mean standardized precipitation index (SPI) (McKee et al. 1993) for 3-month and 9-month time scales, that are indicative of short and long-term droughts. A July 9-month SPI, for example, is an index based on the 9-month average of precipitation from November of the previous year to July of the current year. Consistent with the precipitation index, the two SPI time series also indicate the occurrence of more frequent extremely wet and dry
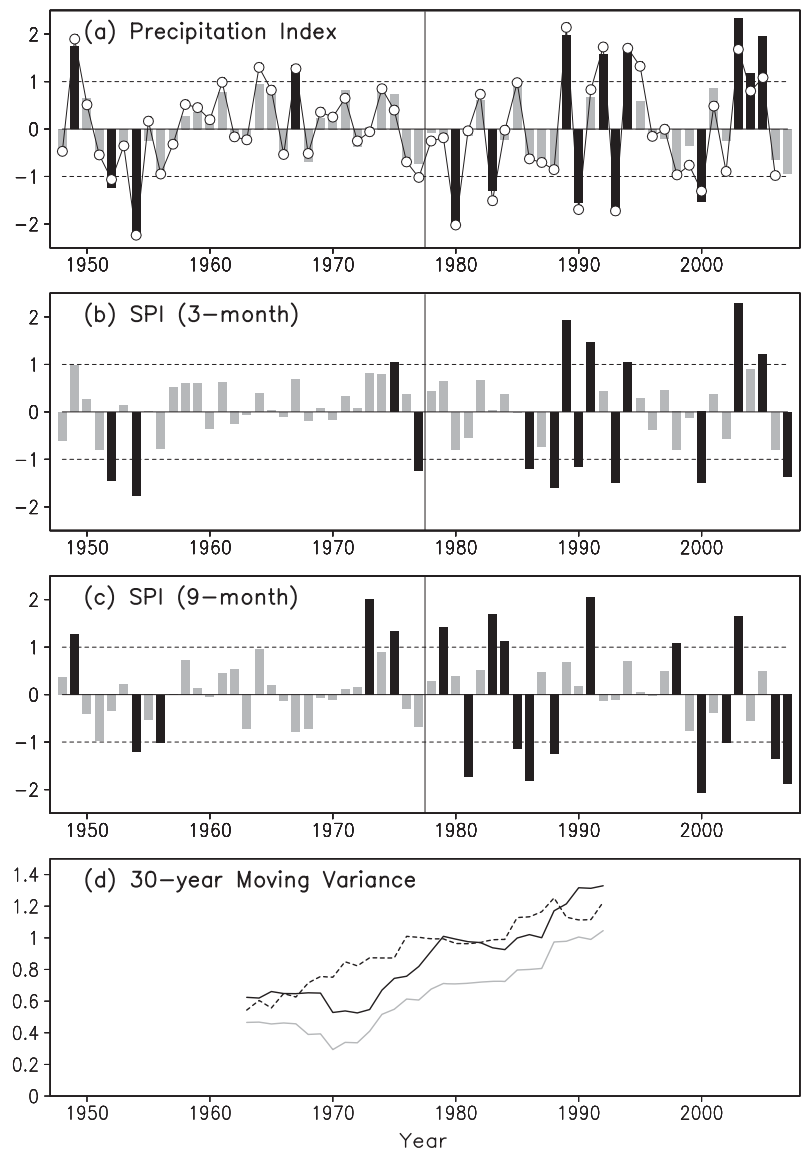

FIG. 2. Normalized time series of JJA mean (a) precipitation anomalies averaged over the southeastern United States $\left(25^{\circ}-\right.$ $36.5^{\circ} \mathrm{N}, 76^{\circ}-91^{\circ} \mathrm{W}$ ) with the CPC rainfall data (bars) and those averaged over the seven Southeast states with station observations (line with open circle) and time series of JJA mean (b) 3-month and (c) 9-month SPI. Black bars in (a)-(c) represent wet (positive) and dry (negative) summers with normalized precipitation anomalies and SPI values exceeding 1, respectively, indicated by dashed lines. A vertical line divides the two 30 -yr periods. (d) Time series of 30-yr moving variance for the normalized Southeast summer rainfall index (solid black), 3-month SPI (solid gray), and 9-month SPI (dotted).

summers for both short and longer time scales in the latter period than in the early period.

Figure $2 \mathrm{~d}$ shows the time series of 30 -yr moving variance of the precipitation index, as well as for the 3-month and 9-month SPI. The variance of each index time series is characterized by a similar trend. The upward trend in precipitation variance indicates that the variability of summer precipitation in the Southeast increased steadily from the 1960s through the 1990s.

It is noted in Fig. 2a that summer rainfall deficits themselves were not the worst for the three Southeast summer droughts mentioned earlier (1986, 2000, and 2007) and precipitation anomalies were less than one standard 


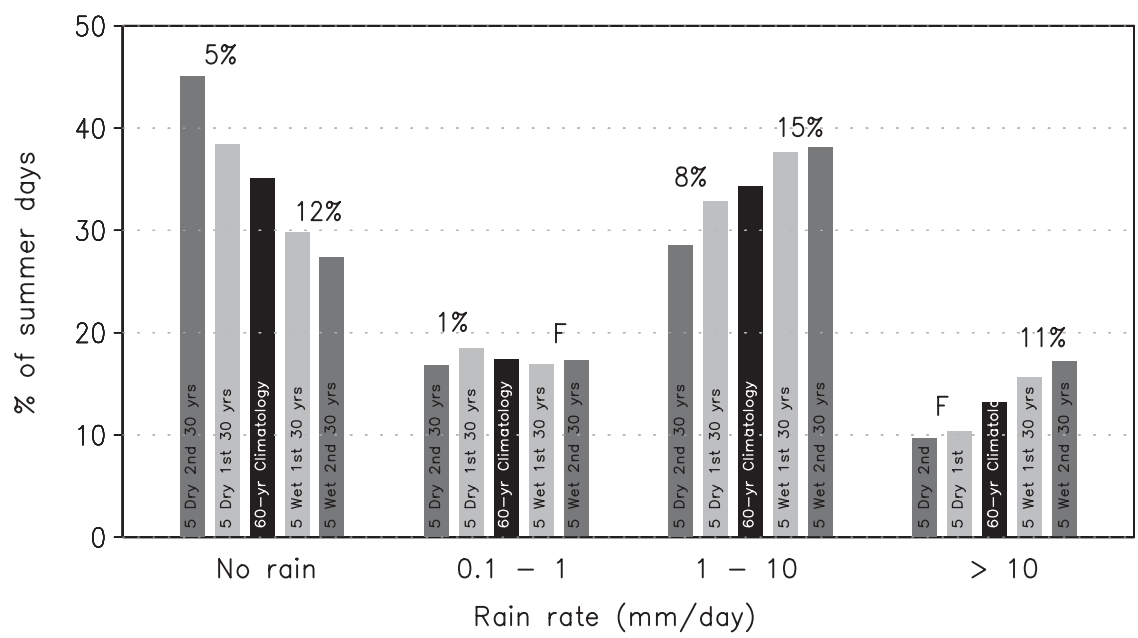

FIG. 3. Percentage of summer days in four rain-rate classes. In each category the black bar is the 60-yr climatological mean and gray bars are the composites of five driest and five wettest summers in the 1948-77 (light gray) and 1978-2007 (dark gray) periods. The percentage at the top of each pair of bars indicates the significance level of the difference in each pair of composites between the two periods, with $\mathrm{F}$ denoting failure of the significance tests, estimated by the Monte Carlo tests with the bootstrap resampling technique.

deviation in JJA 1986 and 2007. The 9-month SPI, however, displays the largest negative values in the three summers (Fig. 2c), indicating that prolonged rainfall deficits starting from prior seasons contributed to the severe summer droughts, rather than only the rainfall deficits in the summer season.

Since the 60-yr rainfall data consist of measurements based on different observational platforms-for example, from both pre- and postsatellite and radar eras-the results presented in Fig. 2 may be sensitive to the changes of the techniques in measuring precipitation over time. To examine this potential effect, a similar precipitation index is constructed using rain gauge observations alone from 164 stations that are available in the U.S. Historical Climatology Network (USHCN) (Williams et al. 2007) with a relatively homogeneous distribution over the seven southeastern states, which is also shown in Fig. 2a. The precipitation index based on the station data is very similar to that based on the CPC precipitation data, with higher rainfall variability in the recent three decades confirming that the Southeast summer rainfall variability has, indeed, intensified since the late 1970s.

The station data from the USHCN has a much longer record, and the Southeast summer precipitation index is extended backward to 1900 and a similar 30-yr moving variance is computed (not shown). It is interesting to note that the interannual variance of Southeast summer precipitation decreased from the early twentieth century to the 1960s and then started to increase afterward.

The relationship between the changes in the characteristics of the interannual variability of seasonal mean summer precipitation and the frequency and intensity of daily rainfalls is examined by classifying the daily rain rates of summer extremes and then comparing them to corresponding long-term values. Figure 3 shows the frequency distribution of summer days with different daily rain rates for the entire 60 summer seasons compared to those of the five wettest and five driest summers in the 1948-77 and 1978-2007 periods. A day with precipitation less than $0.1 \mathrm{~mm}$ day $^{-1}$ is defined as a nonrainy day. For rainy days rainfall intensities are divided into three classes: $0.1 \sim 1,1 \sim 10$, and $>10 \mathrm{~mm}$ day $^{-1}$. In each rainrate class, the number of days between June and August with the appropriate rain rate is averaged over all the grid points in the Southeast domain $\left(25^{\circ}-36.5^{\circ} \mathrm{N}, 76^{\circ}-91^{\circ} \mathrm{W}\right)$ for the years of interest.

The analysis indicates that over the $60 \mathrm{yr}, 35 \%$ of the summer days are nonrainy days. The distributions of summer days in the three rain-rate classes are $18 \%(0.1 \sim 1$ $\left.\mathrm{mm} \mathrm{day}{ }^{-1}\right), 34 \%\left(1 \sim 10 \mathrm{~mm} \mathrm{day}^{-1}\right)$, and $13 \%(>10$ $\mathrm{mm}$ day $\left.^{-1}\right)$, respectively. The overall statistics for individual 30-yr periods (not shown) are similar to those of the $60 \mathrm{yr}$. However, there are considerable differences in the characteristics of daily rainfall for the extremely dry and wet summers over the two 30 -yr periods. As shown in Fig. 3, the number of nonrainy days increases (decreases) in dry (wet) summers. The percentage of nonrainy days varies $9 \%$ between the wet and dry summers in the first $30-y r$ period and increases to $18 \%$ in the second $30-y r$ period. During the extreme summers, the number of rainy days with small rain rates $(0.1 \sim$ $1 \mathrm{~mm} \mathrm{day}{ }^{-1}$ ) does not differ much from the long-term 
mean. However, the number of days with larger rain rates $\left(>1 \mathrm{~mm} \mathrm{day}^{-1}\right)$ is consistently higher in wet summers and lower in dry summers. The difference in the rain rate distribution between wet and dry summers is greater in the second half of the period than in the first half, indicating more extreme rainfall variability for the daily time scale and is consistent with greater variability of seasonal means (Fig. 2a). These changes in the rain rate distribution between the two 30 -yr periods are above the $10 \%$ significance level for dry composites, except for the heavy rain-rate class $\left(>10 \mathrm{~mm} \mathrm{day}^{-1}\right)$ and above the $15 \%$ significance level for wet composites, except for the light rain-rate class $\left(0.1-1 \mathrm{~mm}_{\text {day }}{ }^{-1}\right)$, as estimated by the Monte Carlo tests with the bootstrap resampling technique (e.g., Wilks 1995).

An increase in frequency and intensity of heavy precipitation has previously been observed over the contiguous United States during the past three decades (Groisman et al. 2004). The trend in intense precipitation has been linked to increasing greenhouse gas concentrations (Groisman et al. 2005). The result in Fig. 3 suggests that such a trend in intense rainfall contributes, in part, to the observed increase in summer rainfall variability in the Southeast.

As an important factor in the total continental-scale warm season rainfall in the United States, Southeast summer precipitation is fundamentally controlled by the large-scale atmospheric circulation (Liu et al. 1998). Figure 4 shows both upper- and lower-level circulation anomalies associated with Southeast summer rainfall deficits obtained based on linear regressions of the 60-yr data versus the Southeast summer precipitation index (Fig. 2a). The drought-related circulation is dominated by positive upper-troposphere height anomalies over the central United States and negative zonal wind anomalies over the southern states (Fig. 4a), highlighting the northward shift of the upper-level jet. At the lower level, the anticyclonic circulation enhances the Great Plains lowlevel jet and moisture transport from the Gulf of Mexico to the Midwest, but causes a deficit of moisture flux from the Gulf to the Southeast. The circulation pattern and associated low-level divergence field are consistent with dry conditions in the Southeast and wet conditions in the Midwest. The out-of-phase relationship between precipitation anomalies in the Southeast and the Midwest is one of the major patterns of warm season rainfall variability in the United States and has been identified in previous studies (e.g., Ting and Wang 1997). In the summers of 1993 and 2007, for example, while the Midwest suffered from devastating floods, the Southeast experienced severe droughts.

The change in characteristics of Southeast summer rainfall variability is also closely associated with changes in the upper-level atmospheric circulation variability. Figure 5 shows the 200-hPa zonal wind variance for the two $30-y r$ periods. There is a significant southward shift of the center of maximum zonal wind variance from $45^{\circ} \mathrm{N}$ in the early period to $40^{\circ} \mathrm{N}$ in the late period. Consequently, the zonal wind variability at jet stream level is increased over the southern states in the second $30 \mathrm{yr}$, which is significantly correlated with the Southeast precipitation (Fig. 4a). The changes in the circulation variability are thus dynamically consistent with the intensification of Southeast summer rainfall variability.

\section{b. Covariability with SSTs}

Are changes in the rainfall variability in southeastern United States also related to changes in other features in the climate system, for example, changes in SSTs? To explore this possibility, SVD analyses are performed by analyzing the covariance matrices of summer season U.S. rainfalls and SSTs in the adjacent ocean basins (i.e., Pacific and Atlantic). Table 1 lists the statistics for the first SVD mode with the Pacific SSTs and two leading modes with the Atlantic SSTs, including the percentage of squared covariance explained by each mode, the temporal correlation between each pair of expansion coefficients, and the variance in individual fields that is explained by each mode. The spatial patterns of these SVD modes are shown in Fig. 6 by their homogeneous correlation maps (Wallace et al. 1992).

Most previous studies attribute interannual changes of U.S. summer rainfall to the influence of the El NiñoSouthern Oscillation (ENSO), despite that such an influence is much weaker in summer than in winter. Although this study focuses on the potential influence of Atlantic SSTs, we analyze the relationship between U.S. summer rainfall and Pacific SSTs, first to gain perspective for our subsequent discussion on the Atlantic SSTs.

For the Pacific SSTs, the first SVD mode is characterized by the El Niño SST pattern, with large positive correlations in the eastern and central equatorial Pacific, as well as along the west coast of North America, and negative correlations in the central North Pacific (Fig. 6a). The time series of the expansion coefficient (Fig. 7a) is dominated by interannual variation. The corresponding precipitation (Fig. 6b) displays wet conditions in the northern plains and the Midwest and dry conditions in the Southeast. This is the canonical summer precipitation pattern associated with ENSO, also identified by the same SVD analysis in Ting and Wang (1997). This mode explains $40 \%$ of the squared covariance between the Pacific SSTs and U.S. precipitation, but only explains $7 \%$ of the total summer precipitation variance over the United States and 5\% over the southeastern U.S. domain. 
(a) 200-hPa Height and Zonal Wind
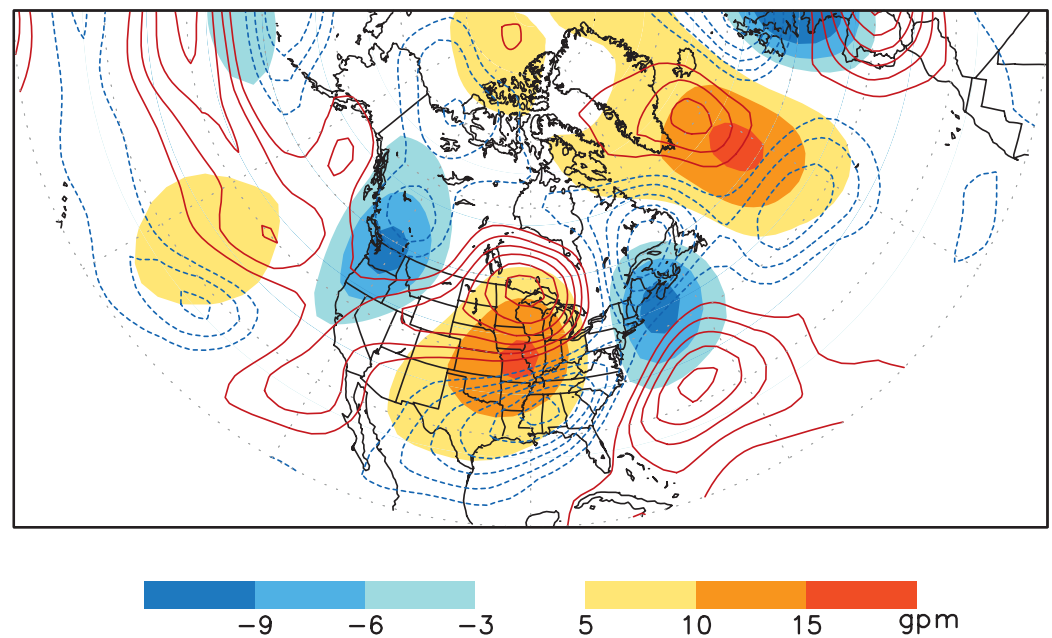

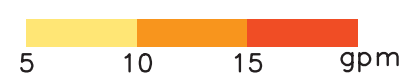

(c) 200-hPa Height

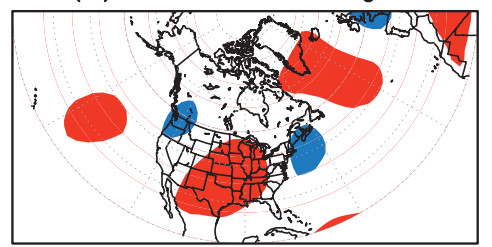

(d) 200-hPa Zonal Wind

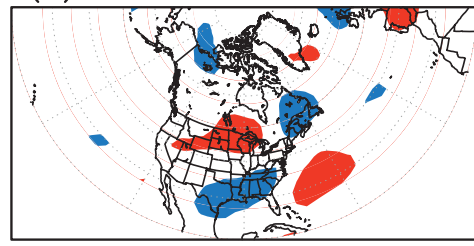

$5 \%$ significance level (b) $850-\mathrm{hPa}$ Wind and $925-\mathrm{hPa}$ Divergence

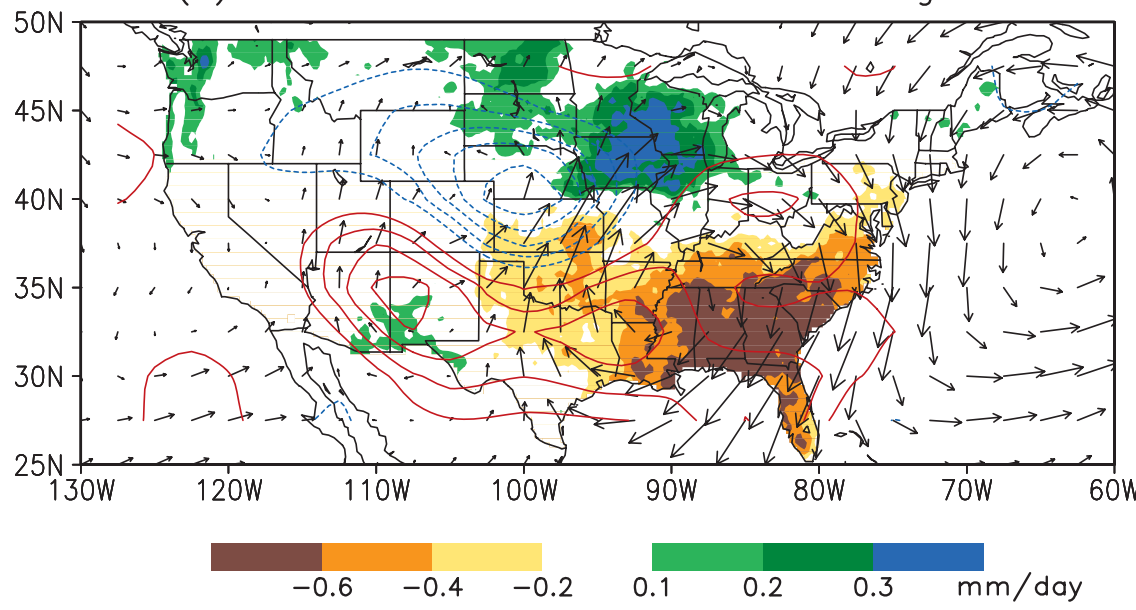

(e) $850-\mathrm{hPa}$ Zonal Wind

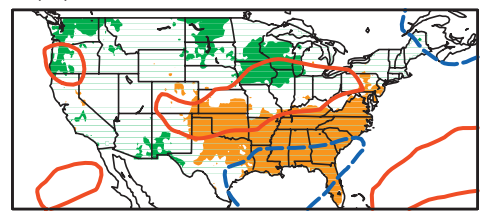

(f) $850-\mathrm{hPa}$ Meridional Wind

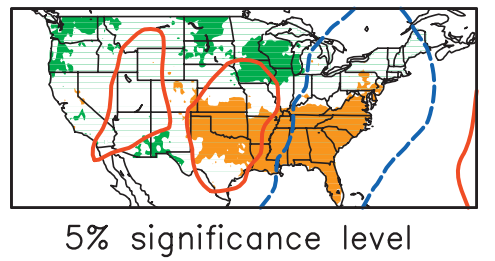

FIG. 4. Composites of JJA seasonal mean anomalous (a) 200-hPa height (shading) and zonal wind (contour) and (b) 850-hPa wind (vector), 925-hPa divergence (contour) and U.S. precipitation (shading) associated with one standard deviation of rainfall deficit in the Southeast summer rainfall index. The anomaly fields are obtained based on linear regressions against the 60-yr Southeast summer precipitation index. Contour intervals are $0.2 \mathrm{~m} \mathrm{~s}^{-1}$ in (a) and $10^{-7} \mathrm{~s}^{-1}$ in (b), with positive contours in red, negative in blue, and zero contours omitted. The statistical significance of the composite anomalies is estimated by the Monte Carlo tests. Regions of positive and negative (c) 200-hPa height and (d) zonal wind anomalies exceeding the 5\% significance level are indicated by red and blue shadings, respectively. Regions of positive and negative (e) 850-hPa zonal and (f) meridional wind anomalies exceeding the 5\% significance level are circled by red and blue lines, respectively. (e),(f) Green (orange) shadings indicate regions of positive (negative) U.S. rainfall anomalies exceeding the $5 \%$ significance level.

For the Atlantic SSTs, the first SVD explains $35 \%$ of the squared covariance between the Atlantic SSTs and U.S. precipitation. The SST pattern (Fig. 6c) features warm SST anomalies across the tropical and North Atlantic with a maximum amplitude in the eastern portion of the basin. The time series of the expansion coefficient shows a nearly linear increase of such a warming (Fig. 7b). This Atlantic warming is also correlated with SST anomalies in the Indo-Pacific warm pool, the region experiencing significant warming in the past $60 \mathrm{yr}$ (e.g., Wang and Mehta 2008). The first mode of precipitation, which explains $10 \%$ of the total summer U.S. precipitation variance and $14 \%$ of the local variance in the Southeast, has a well-defined pattern with positive correlations in the Southeast and the southern plains (Fig. 6d). Associated with the Atlantic warming, summer precipitation in the Gulf states, centered in Texas, is above normal.

The second SVD mode explains $19 \%$ of the squared covariance. The SST pattern (Fig. 6e) displays a band of positive correlations centered at the equator, which closely 
(a) JJA $1948-1977$

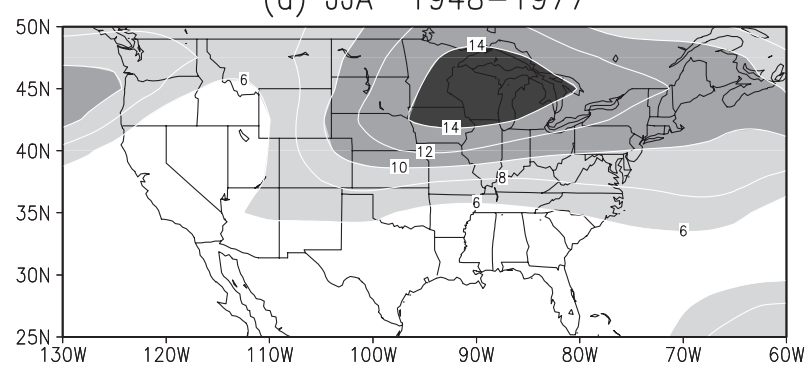

(b) JJA 1978-2007

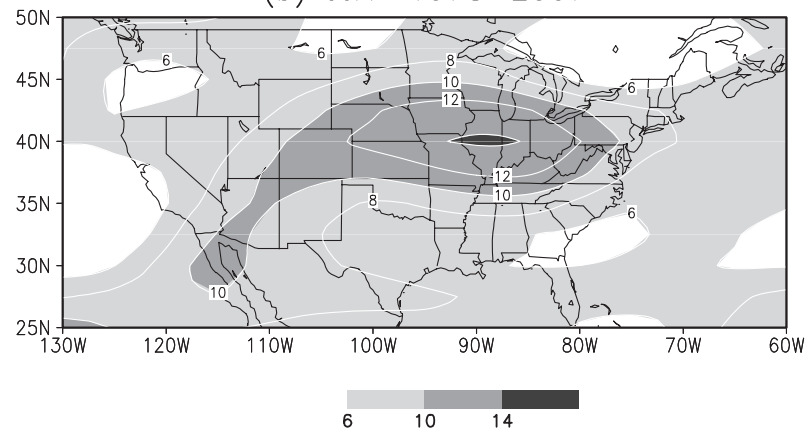

FIG. 5. Interannual variance of 200-hPa zonal wind anomaly for JJA in (a) 1948-77 and (b) 1978-2007. Values greater than $6\left(\mathrm{~m} \mathrm{~s}^{-1}\right)^{2}$ are shaded and contoured with a contour interval of $2\left(\mathrm{~m} \mathrm{~s}^{-1}\right)^{2}$.

resembles the spatial pattern of the Atlantic zonal mode (Zebiak 1993) and its interannual variability increase since the mid-1970s (Fig. 7c). Additionally, a zonal band of positive correlations is found in the North Atlantic centered at $45^{\circ} \mathrm{N}$. The precipitation pattern (Fig. 6f) shows coherent negative correlations in the Southeast, where the summer precipitation index (Fig. 2a) is constructed, and positive correlations in the Midwest. This mode accounts for $9 \%$ of the total U.S. summer precipitation variance and $17 \%$ of the local variance of southeastern U.S. summer rainfall. When the Atlantic zonal mode is in its warm phase, there is a tendency for decreased summer rainfalls across the Southeast. The relationship is consistent with the finding of Enfield (1996), which links tropical North Atlantic SSTs and Southeast rainfall at interannual time scales.

The temporal correlation between the Pacific SST and associated U.S. precipitation time series (Fig. 7a) is 0.63 , highest among the three modes (Table 1). However, this mode explains the least precipitation variance for the southeastern U.S. region. The SST time series (Fig. 7a, dark bars) displays large positive and negative fluctuations in El Niño (e.g., 1957, 1965, 1972, 1983, 1987, 1992, 1993, and 1997) and La Niña (e.g., 1950, 1955, 1964, 1970, 1971, 1973, 1975, 1988, and 1999) years, respectively. A trend toward warmer SSTs starting in the late 1970s is also discernible, as reported by Trenberth and Hurrell (1994). The U.S. precipitation time series shows a trend similar to that of SSTs, indicating a possible increase of wetter conditions in the northern plains and the Midwest, and drier conditions in Georgia, North Carolina, and South Carolina in more recent years.

The correlation between the pair of the first SVD mode time series of Atlantic SSTs and U.S. precipitation (Fig. 7b) is 0.60. Both SSTs and precipitation are dominated by an upward trend, with a shift of SST anomalies from a cold phase to a warm phase in the early 1980s. This coincides with the sign change of the global-mean SST anomaly around the same time (Bernstein et al. 2008). To some extent, this Atlantic SST mode resembles the AMO, especially when the warming trend is removed from Fig. 7b. The detrended time series of SSTs (not shown) is characterized by warm phases prior to the mid1960s and after the mid-1990s and a cold phase in the 1970s and 1980s, similar to the AMO SST index in Sutton and Hodson (2005). The precipitation pattern, with above normal rainfall in the Southeast and East Coast and below normal rainfall in the northern plains and the Pacific Northwest (Fig. 6d), also resembles the composite rainfall pattern between the AMO warm and cold phases (Sutton and Hodson 2005). This mode may contribute to the increase of wet summers since the mid-1980s.

The correlation between the SST and U.S. summer rainfall time series for the Atlantic mode 2 (the Atlantic zonal mode) in Fig. 7c is 0.58 . However, this mode explains most of the summer precipitation variability in the southeastern United States (17\%) among all three SVD modes. The SST and precipitation fluctuations have almost doubled since the late 1970s, indicating that increased variability of the Atlantic zonal mode may make an important contribution to the increased summer rainfall variability over the Southeast (Fig. 6f).

How each SVD mode contributes to the observed increase of summer rainfall variability over the southeastern United States is illustrated in Table 2 by comparing the

TABLE 1. Statistics of three leading SVD modes of SSTs and precipitation (prcp). The percentage of precipitation variance is listed for both the contiguous United States and the Southeast domain (in parentheses).

\begin{tabular}{lcccc}
\hline \hline & Square covariance (\%) & Temporal correlation & SST variance (\%) & Precipitation variance (\%) \\
\hline PCF SST-U.S. prcp mode 1 & 40 & 0.63 & 35 & $7(5)$ \\
ATL SST-U.S. prcp mode 1 & 35 & 0.60 & 23 & $10(14)$ \\
ATL SST-U.S. prcp mode 2 & 19 & 0.58 & 15 & $9(17)$ \\
\hline
\end{tabular}


(a) PCF SST-US Prcp Mode 1

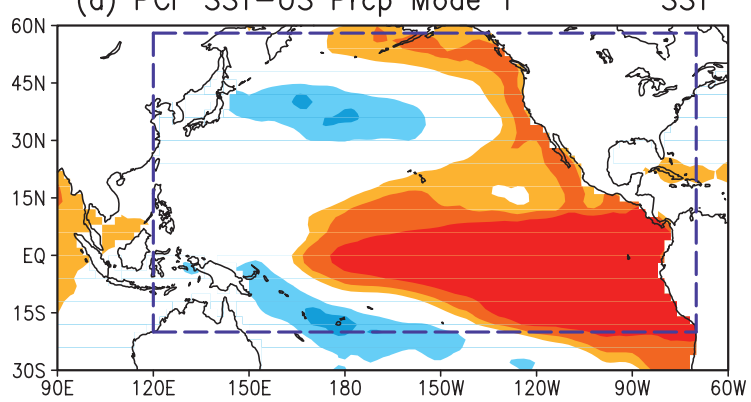

(c) ATL SST-US Prcp Mode 1

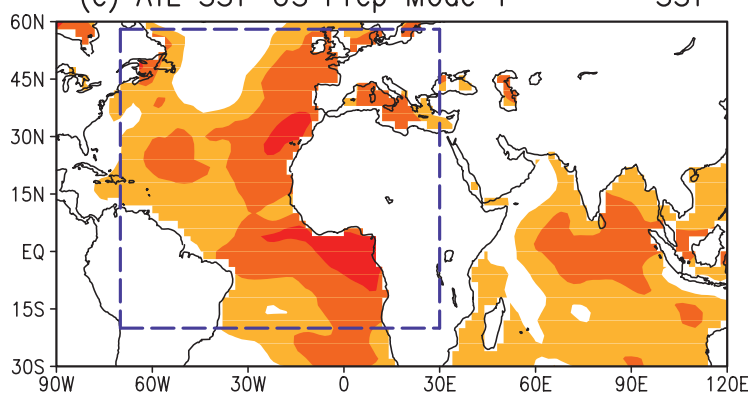

(e) ATL SST-US Prcp Mode 2

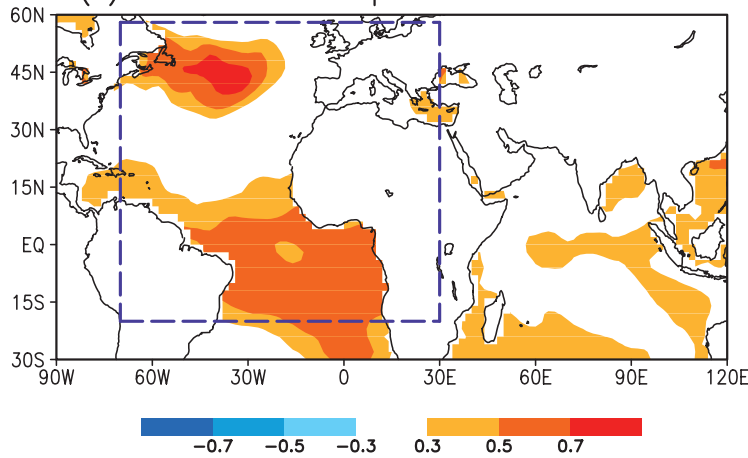

(b) PCF SST-US Prcp Mode 1

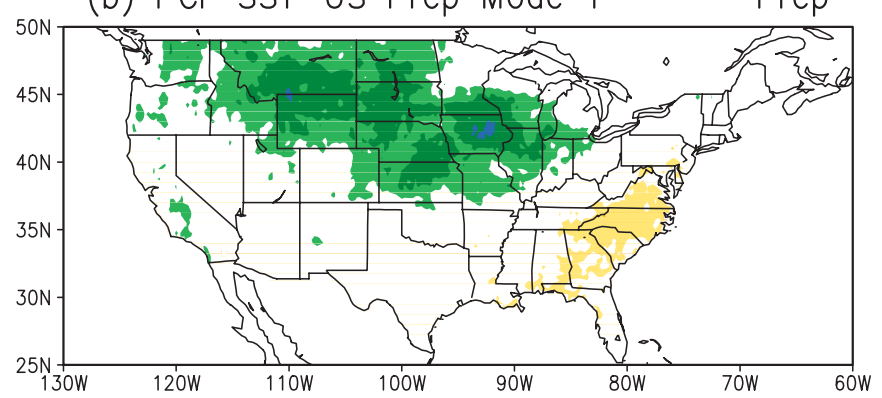

(d) ATL SST-US Prcp Mode 1

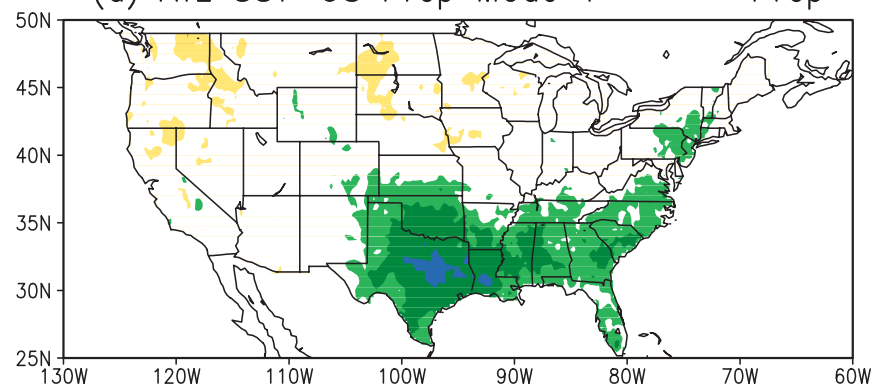

(f) ATL SST-US Prcp Mode 2

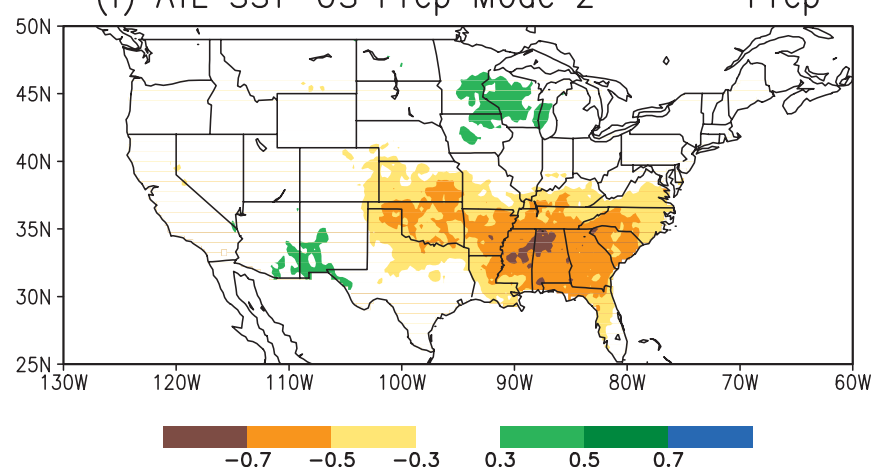

FIG. 6. Homogeneous correlation maps of the (a),(b) first SVD mode between Pacific (PCF) SSTs and U.S. precipitation (Prcp), and the (c),(d) first and (e),(f) second SVD modes between Atlantic (ATL) SSTs and U.S. prcp. Correlation coefficients greater than 0.3 are shaded, which exceed the $5 \%$ significance level estimated by the Monte Carlo tests. The dashed-line boxes indicate regions of SSTs used in the SVD analyses.

contributions of the two 30 -yr periods to the total variance of each SVD time series over the entire $60 \mathrm{yr}$. The increase of the Atlantic SST variability in the recent $30 \mathrm{yr}$ - both in the warming trend and the zonal mode-is consistent with the increase of the precipitation variability in the corresponding modes over the same period. Both SVD modes have stronger loadings over the Southeast in the precipitation field than the first SVD mode with the Pacific SSTs (Fig. 6). Although all three SVD modes of U.S. precipitation increase the rainfall variance from the first $30 \mathrm{yr}$ to the second $30 \mathrm{yr}$, the intensification of the Southeast summer rainfall variability is most likely related to the higher Atlantic SST variability in the recent three decades.
In addition, the higher Atlantic SST variability in the late period also accounts for the change of the atmospheric circulation variability between the two 30-yr intervals (Fig. 5). Figure 8 shows the 200-hPa zonal wind variance associated the Pacific ENSO mode, the SST warming trend, and the Atlantic zonal mode over the two 30-yr periods. They are reconstructed with linear regressions versus the SST time series of each SVD mode. There are significant increases in the upper-level zonal wind variability over the central and southern United States in the second $30 \mathrm{yr}$ associated with the two Atlantic SST modes (Figs. 8d and 8f). These changes contribute to the observed southward shift of the region of maximum zonal wind variability and the larger zonal 
(a) PCF SST-US Prcp Mode 1

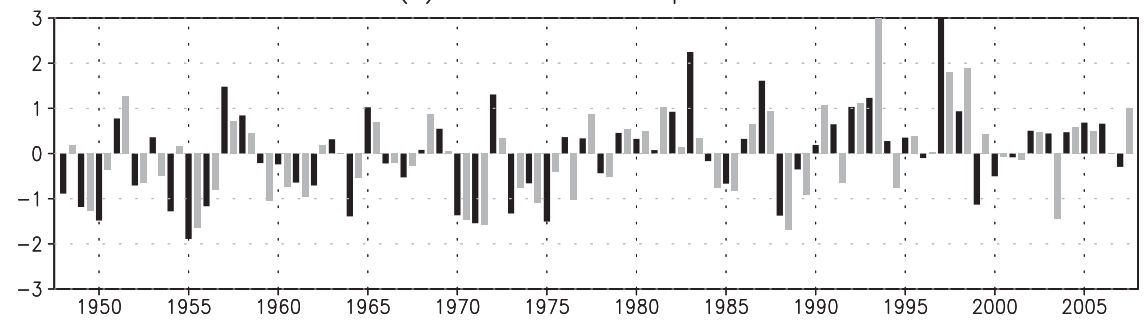

(b) ATL SST-US Prcp Mode 1

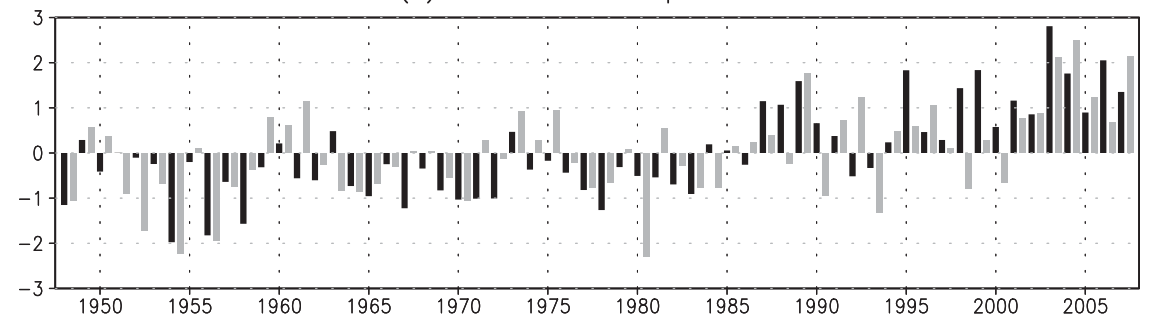

(c) ATL SST-US Prcp Mode 2

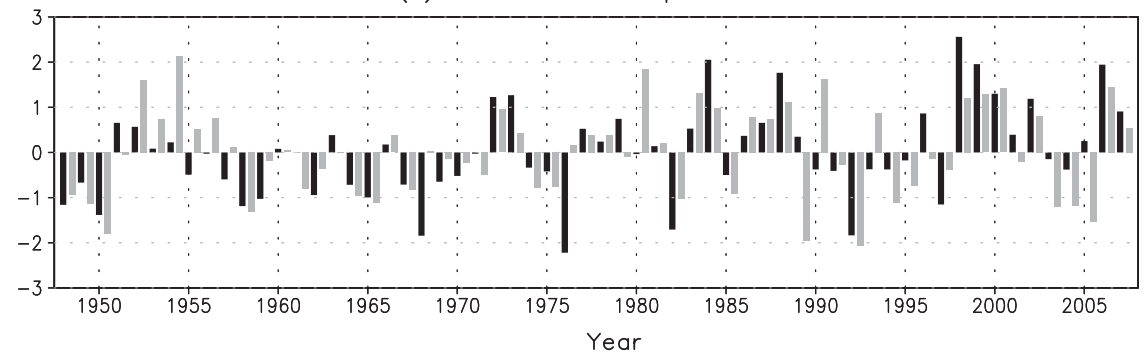

FIG. 7. Normalized time series of the (a) first SVD mode between PCF SSTs (dark bar) and U.S. Prcp (light bar), and the (b) first and (c) second SVD modes between ATL SSTs (dark bar) and U.S. Prcp (light bar).

wind variability over the southern states in the latter period (Fig. 5).

The SVD analyses capture the relation of the U.S. precipitation to the Pacific and Atlantic SSTs. Both Pacific and Atlantic SSTs are also found to covary with runoff (McCabe and Wolock 2008) and the Palmer drought severity index (Apipattanavis et al. 2009) in North America. The correlation of the ENSO SST time series (Fig. 7a) with the time series of the two Atlantic SST modes (Figs. $7 \mathrm{~b}$ and $7 \mathrm{c}$ ) are 0.13 and -0.04 , respectively. This indicates that the two Atlantic SST modes are largely independent of the ENSO mode. The correlation between the detrended time series of the two Atlantic SST modes is 0.27 , suggesting that the interannual variability of the two Atlantic modes is relatively independent. Although all three SVD precipitation patterns (Fig. 6, right) have loadings in the Southeast, they are distinctive in the centers of action. The rainfall patterns coupled with the ENSO SSTs and the SST warming trend (Figs. $6 \mathrm{~b}$ and $6 \mathrm{~d}$ ) emphasize more rainfall variability in the eastern and western parts of the southeastern U.S. domain, respectively, whereas the rainfall pattern coupled with the Atlantic zonal mode (Fig. 6f) focuses on the central part of the Southeast.

Lastly, how the SST-coupled precipitation patterns contribute to the Southeast rainfall variability is assessed

TABLE 2. Percentage of the total variance in each SVD time series over the two 30 -yr intervals.

\begin{tabular}{lcccc}
\hline \hline & $\begin{array}{c}\text { SST variance (\%) } \\
\text { First 30 yr }\end{array}$ & $\begin{array}{c}\text { Prcp variance (\%) } \\
\text { First 30 yr }\end{array}$ & $\begin{array}{c}\text { SST variance (\%) } \\
\text { Second 30 yr }\end{array}$ & $\begin{array}{c}\text { Prcp variance (\%) } \\
\text { Second 30 yr }\end{array}$ \\
\hline PCF SST-U.S. prep mode 1 & 51 & 35 & 49 & 65 \\
ATL SST-U.S. prcp mode 1 & 35 & 39 & 65 & 61 \\
ATL SST-U.S. prcp mode 2 & 39 & 37 & 61 & 63 \\
\hline
\end{tabular}


(a) JJA 1948-1977

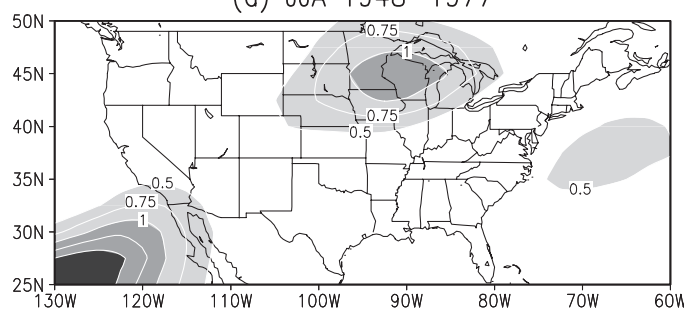

(c) JJA 1948-1977

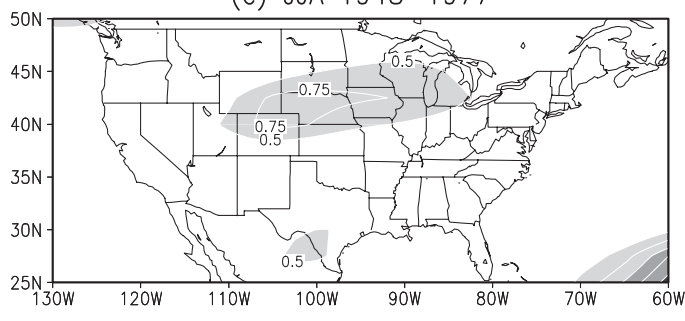

(e) JJA 1948-1977

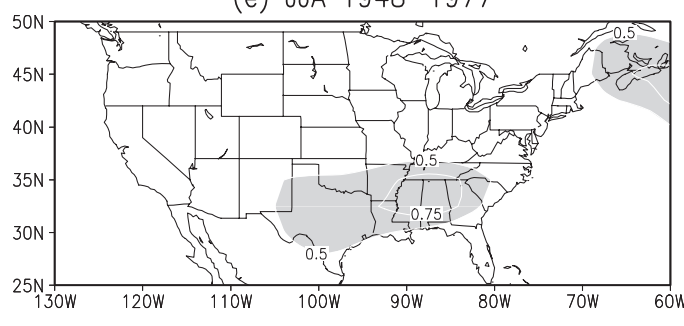

(b) JJA 1978-2007

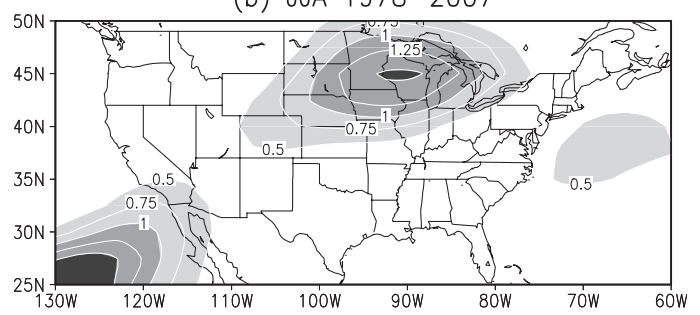

(d) JJA 1978-2007

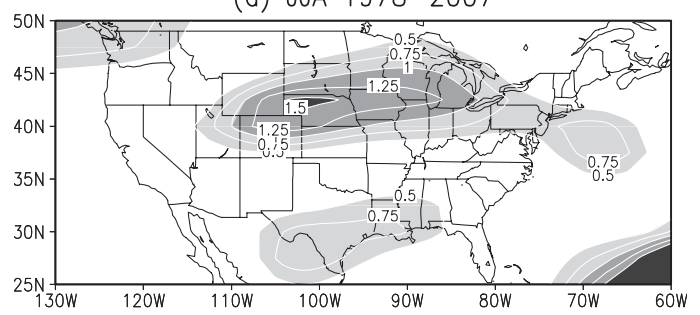

(f) JJA 1978-2007

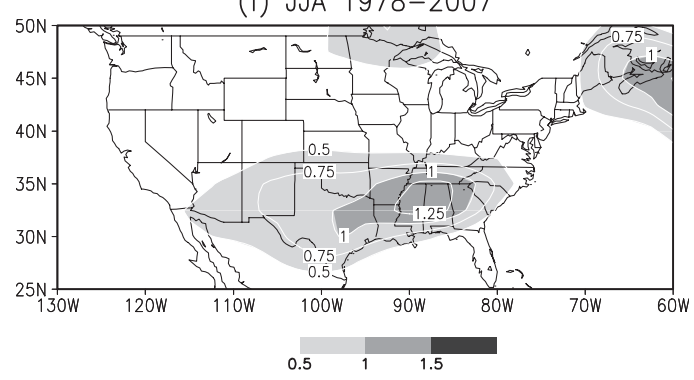

FIG. 8. Interannual variance of 200-hPa zonal wind anomaly associated with the (a),(b) ENSO mode, (c),(d) SST warming trend, and (e),(f) ATL zonal mode for JJA in (left) 1948-77 and (right) 1978-2007. Values greater than 0.5 $\left(\mathrm{m} \mathrm{s}^{-1}\right)^{2}$ are shaded and contoured with a contour interval of $0.25\left(\mathrm{~m} \mathrm{~s}^{-1}\right)^{2}$.

by reconstructing the Southeast precipitation index based on multiple linear regressions against the three SVD precipitation time series. As shown in Fig. 9, the reconstructed total rainfall anomalies reproduce well the observed precipitation variation with a correlation $R=0.92$. Among the three SVD modes, the Atlantic zonal-mode-related precipitation change contributes most to the Southeast rainfall variability $(R=0.87)$. The warming trend also has a significant contribution $(R=0.63)$, whereas the ENSO mode contributes the least $(R=0.39)$. Note that the threshold for the correlation coefficients exceeding the $1 \%$ significance level is 0.29 based on Monte Carlo tests. Among the 15 wet and dry summers with the precipitation index exceeding one standard deviation (Fig. 2a, black bars), the ENSO mode only dominates the 1993 drought. The rest of the 14 summers are dominated by the Atlantic zonal mode. On average, for the 15 summers, the precipitation pattern correlated with the Atlantic zonal mode accounts for $70 \%$ of the reconstructed Southeast rainfall anomalies, while those correlated with the warming trend and the ENSO mode account for $22 \%$ and $8 \%$, respectively.

\section{Conclusions and discussions}

Our analysis of the 60-yr rainfall data reveals that the interannual variability of summer precipitation in the southeastern United States intensified in the recent three decades (1978-2007) when compared to the earlier three decades (1948-77), leading to stronger summer droughts and pluvials. Such intensification of summer rainfall variability is contributed by a larger decrease of light to medium rainfall events in dry summers and an increase in frequency of heavy rainfall in wet summers in the latter 30 -yr period. Changes in rainfall characteristics are also accompanied by a southward shift of the region of maximum zonal-wind variability at the jet stream level.

The SVD analysis is applied to the 60 -yr summer U.S. precipitation with the Pacific SSTs and the Atlantic SSTs separately. Three precipitation patterns are objectively identified, all of which have significant loadings in the Southeast. The Atlantic zonal mode has the strongest loading in the southeastern United States (17\%) and accounts for $70 \%$ of the precipitation variation, as represented by these three modes. The Atlantic warming mode 


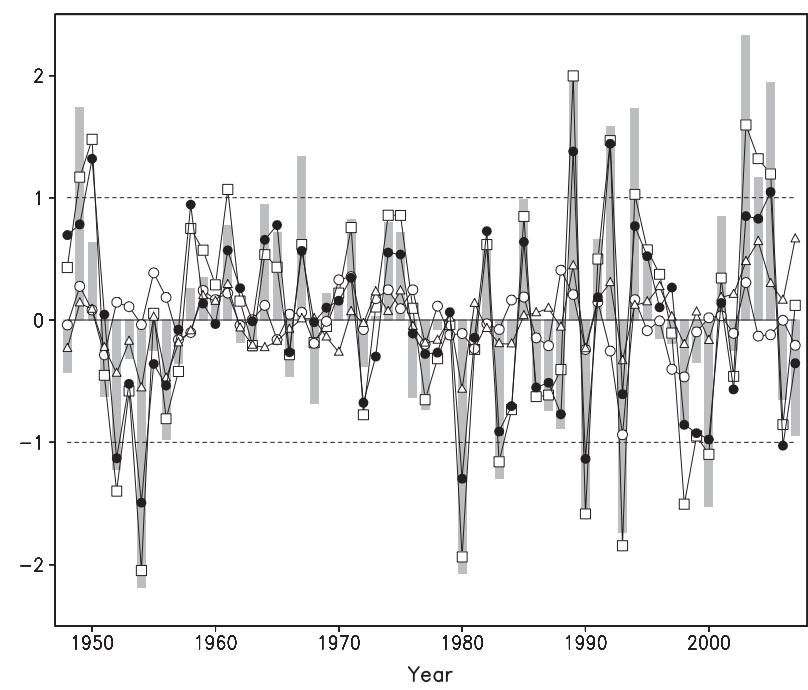

FIG. 9. Observed (bar) and reconstructed (open square) Southeast summer precipitation index based on multiple linear regressions vs the time series of the three SVD precipitation modes. Open circle, triangle, and closed circle indicate rainfall anomalies associated with individual SVD prcp modes that are coupled with the ENSO SST, the SST warming trend, and the ATL zonal mode, respectively.

ranks second in terms of its influence on Southeast summer rainfall variations $(14 \%)$ and may have important contributions to the increased intensity of wet summers since the mid-1980s. The two Atlantic SST modes show higher interannual variability in the recent $30 \mathrm{yr}$, consistent with the intensification of Southeast summer rainfall variability, and account for the observed southward shift of the upper-level maximum zonal wind variability in the latter period. In contrast, the ENSO mode contributes the least $(5 \%)$ to the summer rainfall variation in the southeastern United States. The SST anomalies associated with this mode do not show increased variability; thus, this mode contributes marginally to the increased variation of Southeast U.S. summer rainfall in the recent three decades.

The intensification of the Southeast summer precipitation variability is closely linked to higher Atlantic SST variability in the recent three decades. However, the question of what causes the increase of the Atlantic SST variability and the Southeast rainfall variability, especially in terms of natural climate variability and anthropogenic forcing, remains to be answered. Using tree ring records, Stahle and Cleaveland (1992) suggested that decade-long extreme droughts may have been a prominent feature in the southeastern United States over the past 1000 years. Recent studies also show that the AMO as the natural mode has been an important driver of multidecadal droughts in the United States (McCabe et al. 2004; Sutton and Hodson 2005). Possible mechanisms may also involve changes in atmospheric mean circulation in response to the warming of tropical North Atlantic SST (Kushnir et al. 2010) and consequentially lead to a shift of zonal wind variability (Figs. 5 and 8 ).

On the other hand, the 1978-2007 period corresponds with an overall warming of global tropical SST, and the pattern of the SST warming in the Atlantic resembles that of the linear warming trend observed and simulated by climate models with increasing atmospheric $\mathrm{CO}_{2}$ during the last few decades (Hegerl et al. 2007). Thus, both the increase of the Atlantic SST variability and the Southeast rainfall variability could be a manifestation of global warming in the observational record. In fact, the Intergovernmental Panel on Climate Change (IPCC; Bernstein et al. 2008) projected that in the twenty-first century increasing heavy rains and extreme droughts will be one of the consequences of global warming. A global coupled climate model also shows that the increase in greenhouse gases would produce more frequent and more intense heat waves in the southern United States (Meehl and Tebaldi 2004), which could lead to higher rates of evaporation, drying out the soil, and increasing the probability of severe droughts. Further modeling and diagnostic studies are needed to understand the reasons behind recent changes in the precipitation characteristics in the U. S. Southeast and to discern if changes are due to natural variability in climate system, and are thus reversible, or are due to anthropogenic causes and are expected to continue and intensify.

Acknowledgments. This work was supported by the NOAA Climate Prediction Program for the Americas (CPPA) Grant GC06-246. The NOAA ERSST version 3 data and NCEP-NCAR reanalysis data are provided by the NOAA/OAR/ESRL/PSD, Boulder, Colorado, from their Web site (available at http://www.cdc.noaa. gov). We thank Drs. Douglas Le Comte, Robert E. Dickinson, and Scott J. Weaver; three anonymous reviewers; and the editor for their insightful and constructive comments and suggestions.

\section{REFERENCES}

Apipattanavis, S., G. J. McCabe, B. Rajagopalan, and S. Gangopadhyay, 2009: Joint spatiotemporal variability of global sea surface temperatures and global Palmer drought severity index values. J. Climate, 22, 6251-6267.

Bergman, K. H., C. F. Ropelewski, and M. S. Halpert, 1986: The record southeast drought of 1986. Weatherwise, 39, 262-266.

Bernstein, L., and Coauthors, Eds., 2008: Summary for policymakers. Climate Change 2007: Synthesis Report, Cambridge University Press, 1-22.

Bretherton, C. S., C. Smith, and J. M. Wallace, 1992: An intercomparison of methods for finding coupled patterns in climate data. J. Climate, 5, 541-560. 
Chang, F. C., and J. M. Wallace, 1987: Meteorological conditions during heat waves and droughts in the United States Great Plains. Mon. Wea. Rev., 115, 1253-1269.

Curtis, S., 2008: The Atlantic multidecadal oscillation and extreme daily precipitation over the US and Mexico during the hurricane season. Climate Dyn., 30, 343-351.

Enfield, D. B., 1996: Relationships of inter-American rainfall to tropical Atlantic and Pacific SST variability. Geophys. Res. Lett., 23, 3305-3308.

— A. M. Mestas-Nuñez, and P. J. Trimble, 2001: The Atlantic Multidecadal Oscillation and its relation to rainfall and river flows in the continental U.S. Geophys. Res. Lett., 28, $2077-$ 2088.

Groisman, P. Ya., R. W. Knight, T. R. Karl, D. R. Easterling, B. Sun, and J. H. Lawrimore, 2004: Contemporary changes of the hydrological cycle over the contiguous United States: Trends derived from in situ observations. J. Hydrometeor., 5, 64-85.

$\longrightarrow,-$, D. R. Easterling, T. R. Karl, G. C. Hegerl, and V. N. Razuvaev, 2005: Trends in intense precipitation in the climate record. J. Climate, 18, 1326-1350.

Hegerl, G. C., and Coauthors, 2007: Understanding and attributing climate change. Climate Change 2007: The Physical Science Basis, S. Solomon, Eds., Cambridge University Press, 665-745.

Higgins, R. W., and Coauthors, 2003: Progress in Pan American CLIVAR Research: The North American Monsoon System. Atmósfera, 16, 29-65.

$\mathrm{Hu}, \mathrm{Q}$., and S. Feng, 2001: Variations of teleconnections of ENSO and interannual variations in summer rainfall in the central United States. J. Climate, 14, 2469-2480.

Kalnay, E., and Coauthors, 1996: The NCEP/NCAR 40-Year Reanalysis Project. Bull. Amer. Meteor. Soc., 77, 437-471.

Karl, T. R., and P. J. Young, 1987: The 1986 Southeast drought in historical perspective. Bull. Amer. Meteor. Soc., 68, 773-778.

Kushnir, Y., R. Seager, M. Ting, N. Naik, and J. Nakamura, 2010: Mechanisms of tropical Atlantic SST influence on North American precipitation variability. J. Climate, in press.

Laird, K. R., S. C. Fritz, K. A. Maasch, and B. F. Cumming, 1996: Great drought intensity and frequency before AD 1200 in the Northern Great Plains, USA. Nature, 384, 552-554.

Liu, A. Z., M. Ting, and H. Wang, 1998: Maintenance of circulation anomalies during the 1988 drought and 1993 floods over the United States. J. Atmos. Sci., 55, 2810-2832.

McCabe, G. J., and D. M. Wolock, 2008: Joint variability of global runoff and global sea surface temperatures. J. Hydrometeor., 9, 816-824.

—, M. A. Palecki, and J. L. Betancourt, 2004: Pacific and Atlantic Ocean influences on multidecadal drought frequency in the United States. Proc. Natl. Acad. Sci. USA, 101, 4136-4141.

McKee, T. B., N. J. Doesken, and J. Kleist, 1993: The relationship of drought frequency and duration to time scales. Preprints, Eighth Conf. on Applied Climatology, Anaheim, CA, Amer. Meteor. Soc., 179-184.
McKissick, J. C., B. A. Doherty, R. J. Teasley, and B. Given, 2000: Estimating drought 2000's cost on Georgia's agriculture and rural economy. Center for Agribusiness and Economic Development, University of Georgia, Center Special Rep. 11, 40 pp. [Available online at http://www.caed.uga.edu/publications/ 2000/pdf/CR-00-11.pdf.]

Meehl, G. A., and C. Tebaldi, 2004: More intense, more frequent, and longer lasting heat waves in the 21st Century. Science, 305, 994-997.

Mo, K. C., and J. E. Schemm, 2008: Drought and persistent wet spells over the United States and Mexico. J. Climate, 21, 980-994.

Namias, J., 1983: Some causes of United States drought. J. Climate Appl. Meteor., 22, 30-39.

Seager, R., A. Tzanova, and J. Nakamura, 2009: Drought in the Southeastern United States: Causes, variability over the last millennium and the potential for future hydroclimate change. J. Climate, 22, 5021-5045.

Smith, T. M., R. W. Reynolds, T. C. Peterson, and J. Lawrimore, 2008: Improvements to NOAA's historical merged landocean surface temperature analysis (1880-2006). J. Climate, 21, 2283-2296.

Stahle, D. W., and M. K. Cleaveland, 1992: Reconstruction and analysis of spring rainfall over the southeastern U.S. for the past 1000 years. Bull. Amer. Meteor. Soc., 73, 1947-1961.

Sutton, R. T., and L. R. Hodson, 2005: Atlantic Ocean forcing of North American and European summer climate. Science, 309, 115-118.

Ting, M., and H. Wang, 1997: Summertime U.S. precipitation variability and its relation to Pacific sea surface temperature. J. Climate, 10, 1853-1873.

Trenberth, K. E., and J. Hurrell, 1994: Decadal atmosphere-ocean variations in the Pacific. Climate Dyn., 9, 303-319.

Wallace, J. M., C. Smith, and C. S. Bretherton, 1992: Singular value decomposition of wintertime sea surface temperature and 500-mb height anomalies. J. Climate, 5, 561-576.

Wang, H., and M. Ting, 2000: Covariabilities of winter U.S. precipitation and Pacific sea surface temperatures. J. Climate, 13, 3711-3719.

_ warm pool and its association with atmospheric and oceanic variability in the NCEP-NCAR and SODA reanalyses. J. Climate, 21, 5545-5565.

Wilks, D. S., 1995: Statistical Methods in the Atmospheric Sciences. Academic Press, 467 pp.

Williams, C. N., Jr., M. J. Menne, R. S. Vose, and D. R. Easterling, cited 2007: United States Historical Climatology Network monthly temperature and precipitation data. Carbon Dioxide Information Analysis Center Rep. ORNL/CDIAC-118, NDP019. [Available online at http://cdiac.ornl.gov/epubs/ndp/ushcn/ usa_monthly.html.]

Zebiak, S. E., 1993: Air-sea interaction in the equatorial Atlantic region. J. Climate, 6, 1567-1586. 